Proc. Estonian Acad. Sci. Eng., 2003, 9, 4, 293-303

\title{
Spray parameter optimization and tribological properties of thermally sprayed quasicrystalline and partially quasicrystalline coatings
}

\author{
Erja Turunen $^{\mathrm{a}}$, Tommi Varis ${ }^{\mathrm{a}}$, Kari Vierimaa ${ }^{\mathrm{b}}$, and Simo-Pekka Hannula ${ }^{\mathrm{a}}$ \\ a VTT Industrial Systems, PO.Box 1703, 02044 VTT, Finland; Erja.Turunen@vtt.fi \\ b Metso Field Systems Oy, PO.Box, 00811 Helsinki, Finland
}

Received 24 October 2003

\begin{abstract}
Good tribological properties and low coefficient of friction have previously been reported for thermally sprayed quasicrystalline coatings. In this paper HVOF spray parameter optimization and tribological properties of quasicrystalline coatings, manufactured from three different compositions, is discussed. On-line diagnostics measurements and splat studies were performed to optimize spray parameters of HVOF. Quasicrystalline coatings were produced and the coating microstructure was analysed. Large amount of wear and friction tests were performed to determine the tribological properties of quasicrystalline coating. Relatively high values of the coefficient of friction were obtained in the PoD-test. These tests yielded friction values varying typically between $0.4-0.6$ independent of the counter material.
\end{abstract}

Key words: high velocity oxy-fuel (HVOF) spraying, quasicrystalline coatings, friction, wear, microstructure.

\section{INTRODUCTION}

Quasicrystalline materials are interesting candidates for coating applications due to their unique combination of properties. Their high hardness, low friction under certain conditions, reduced surface energy in comparison with crystalline metals and their oxides, extremely low thermal and electrical conductivity, and plasticity at elevated temperatures are important in various applications $\left[{ }^{1-3}\right]$.

In quasicrystalline materials a repeating periodicity in the atom arrangement exists together with a rotational symmetry forbidden for crystalline materials; fivefold, eightfold, tenfold, and even twelvefold symmetries have been encountered $\left[{ }^{4}\right]$. Since the first observation of a fivefold symmetry in a rapidly solidified Al-Mn alloy in 1984, an intense research of quasicrystals has taken 
place and various methods to prepare quasicrystalline phases in addition to the original method of fabrication, the melt spinning technique, have been developed. These include a number of different manufacturing methods making use of the variety of solidification rates of melt, powder metallurgical processes, and coating techniques. Among the coating techniques, thermal spraying has been shown to be a versatile method for producing thick quasicrystalline coatings $\left[{ }^{1,5-7}\right]$.

Very low coefficient of friction and good tribological properties have been reported previously for the quasicrystalline coatings $\left[{ }^{1,8}\right]$. This paper reports new data related to tribological properties of a series of thermally sprayed quasicrystalline and partially quasicrystalline coatings.

\section{EXPERIMENTAL SET-UP}

\subsection{Spray powders}

In the present study, commercial gas atomized spray powders, manufactured by Saint-Gobain Advanced Ceramics SNMI, France, were used. Three different quasicrystalline materials, $\mathrm{Al}-\mathrm{Cu}-\mathrm{Fe}(\mathrm{F} 1), \mathrm{Al}-\mathrm{Cu}-\mathrm{Fe}-\mathrm{Cr}(\mathrm{A} 1 / \mathrm{S})$, and $\mathrm{Al}-\mathrm{Co}-\mathrm{Fe}-\mathrm{Cr}$ (BT1) were studied. The composition of the F1 powder, given by the manufacturer, was $40.8 \mathrm{wt} \% \mathrm{Al}, 41.2 \mathrm{wt} \% \mathrm{Cu}, 17.0 \mathrm{wt} \% \mathrm{Fe}$, and $0.8 \mathrm{wt} \% \mathrm{~B}$. The composition of the $\mathrm{A} 1 / \mathrm{S}$ powder was $54.1 \mathrm{wt} \% \mathrm{Al}, 17.8 \mathrm{wt} \% \mathrm{Cu}, 13.0 \mathrm{wt} \% \mathrm{Fe}$, and $14.9 \mathrm{wt} \% \mathrm{Cr}$, and of the third powder BT1 - $52.8 \mathrm{wt} \% \mathrm{Al}, 20.4 \mathrm{wt} \% \mathrm{Co}$, $15.3 \mathrm{wt} \% \mathrm{Fe}$, and $11.2 \mathrm{wt} \% \mathrm{Cr}$. Particle size, specified by the powder manufacturer for the powders, was $20-53 \mu \mathrm{m}$. Before HVOF spray tests the powders were studied by SEM and their particle size distribution was measured by Lecotrac LT-100 particle size analyser.

\subsection{Spray parameter optimization}

Since quasicrystalline coatings have proved to be very sensitive for spraying conditions, spray parameters were optimized by using an on-line spray diagnostic system (SprayWatch 2i) to minimize the amount of unwanted phase transformations. Spray tests were carried out by using Praxair HV-2000 HVOF gun. The gun was run from a Model 3440 console utilizing Plasmatron 1262 volumetric powder feeder. Nitrogen was used as a carrier gas, along with the hydrogen as fuel gas.

The melting stage of the particles was studied from splats, formed by quenching of single particles. The substrate used in these tests was polished stainless steel.

To be able to understand the relationship between spray diagnostic results and the coating phase structure, differential thermal analysis (DTA) of the powders was carried out. Equipment used was Perkin-Elmer DTA 7. The temperature cycle was from 20 to $1400^{\circ} \mathrm{C}$ and back in shield gas with a temperature change rate $10^{\circ} \mathrm{C} / \mathrm{s}$. 


\subsection{HVOF deposition of the coatings}

The quasicrystalline coatings were deposited on low carbon steel substrates. A two-axis traverse unit was used to manipulate the gun and substrates during coating deposition.

\subsection{Characterization of the coating layer}

Structural analysis of the coatings were performed by X-ray diffraction, optical microscopy, scanning electron microscopy, and analytical transmission electron microscopy. These studies are published in detail elsewhere $\left[{ }^{9,10}\right]$.

\subsection{Tribological tests}

Three different kinds of tests were used to study the tribological properties of the coatings. Coefficient of friction was determined by using the Pin-on-Disc test method at room temperature and at $500^{\circ} \mathrm{C}$. The test was carried out according to the standard ASTM 99. In the test, a ball with a radius of $50 \mathrm{~mm}$ is pressed against the rotating disc with a fixed force and the corresponding lateral (frictional) force is measured. Used force was $2 \mathrm{~N}$, and sliding velocity $25 \mathrm{~mm} / \mathrm{s}$. After the test the wear tracks were recorded. Various counter materials were used as Fe52, M2 tool steel, $\mathrm{Al}, \mathrm{Cu}$, and DLC.

Another type of test was carried out to study the influence of contact pressure and temperature on friction and wear. This test is schematically shown in Fig. 1. It is specifically designed for studying the valve materials. During the tests the contact pressure was varied between 5 and $30 \mathrm{MPa}$, while the surfaces were rubbed against each other in a torsional mode. Tests were carried out at room temperature and at $500^{\circ} \mathrm{C}$. Diameter of the test buttons was $24 \mathrm{~mm}$. Counter material used in these tests was $\mathrm{HVOF}$ sprayed $\mathrm{Cr}_{3} \mathrm{C}_{2}-\mathrm{NiCr}$.

Scratch test was performed for some coatings. Diamond indenter with a radius of curvature of $0.2 \mathrm{~mm}$ (Rockwell C-indenter) was used. The normal force was $2 \mathrm{~N}$ and sliding velocity $10 \mathrm{~mm} / \mathrm{min}$. Main purpose of these tests was to make a comparison with the test results reported previously [ $\left.{ }^{1}\right]$.

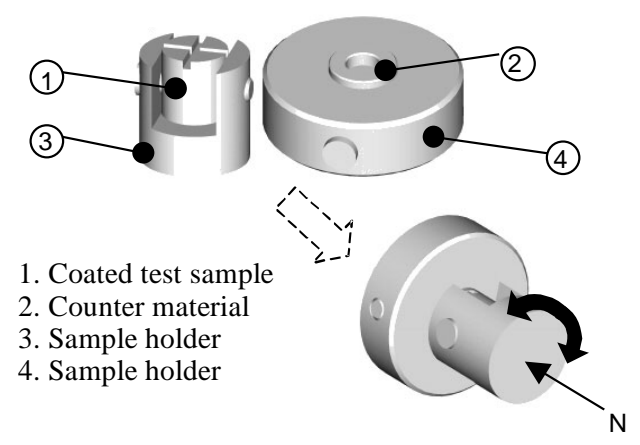

Fig. 1. Schematic illustration of the button test. 


\section{RESULTS}

\subsection{Powder analysis}

Powder morphology is presented in Fig. 2. Measurement of the particle size fraction showed that powders F1 and A1/S were coarser than indicated by the manufacturer's specifications. Both powders have X10 value of $30 \mu \mathrm{m}$ and X90 value of $59 \mu \mathrm{m}$. Powder BT1 was very close to the fraction given by powder manufacturer, having X10 value of $23 \mu \mathrm{m}$ and X90 value of $50 \mu \mathrm{m}$. A detailed analysis of the phase structure of the powders is published elsewhere $\left[{ }^{9,10}\right]$.

\subsection{Differential thermal analysis}

Differential thermal analysis showed that all three powders melted nearly completely in the temperature range of $800-1150^{\circ} \mathrm{C}$. Recrystallization occurred in the temperature range of $950-1100^{\circ} \mathrm{C}$. Powder BT1 has the most predictable behaviour, melting (endothermic peaks) at the temperatures of $1100-1150{ }^{\circ} \mathrm{C}$ and recrystallizing rapidly at the temperature of $1100^{\circ} \mathrm{C}$.

Powders F1 and A1/S have some exothermic peaks also in the lower temperature range $\left(900-400^{\circ} \mathrm{C}\right)$ indicating formation of other phases during slow cooling. For the powder F1 different cubic phases based on aluminum and iron were observed.

\subsection{Diagnostic studies}

A large number of diagnostic measurements were carried out for all the three powders. In these measurements the $\mathrm{H}_{2} / \mathrm{O}_{2}$ gas ratio, total gas flow, and the stand-off distance were varied. Total gas flow was kept standard (900 1/min) and hydrogen/ oxygen ratio was varied. Four different ratios from 2.21 to 3.19 were used. Particle temperatures and velocities were recorded at different stand-off distances for all gas ratios.

The results for powder BT1 with HV 2000 spray gun are presented in Fig. 3. The details of the optimization procedure for other powders are published elsewhere $\left[{ }^{11}\right]$.

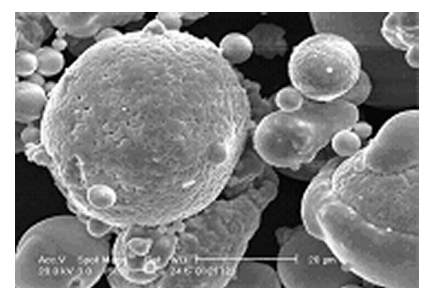

F1

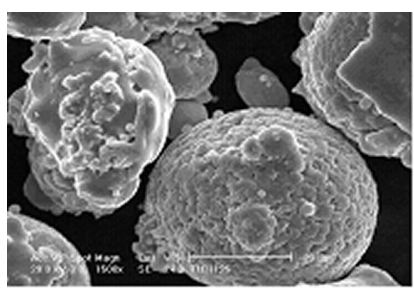

A1/S

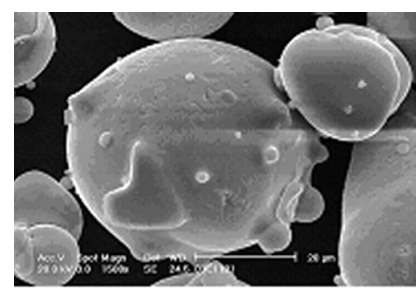

BTI

Fig. 2. Morphology of the test powders. 


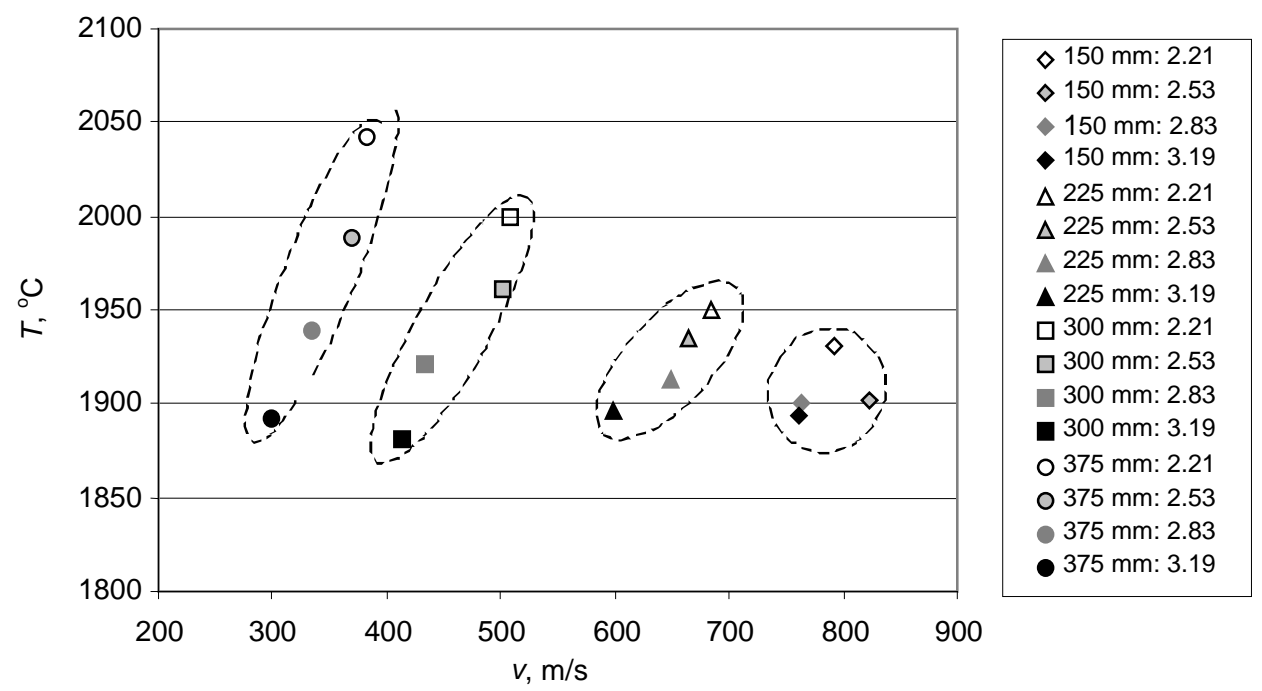

Fig. 3. Diagnostic studies; the table gives the stand-off distances and hydrogen/oxygen ratios.

\subsection{Splat studies and spray parameter optimization}

Based on the diagnostic studies, two different spray conditions, presented in Table 1, were selected for further investigations. The aim of this selection was to study differences in particle melting behaviour at different velocity-temperature stages. The different splat morphologies for the powder BT1 made with the HV 2000 spray gun are presented in Fig. 4. Detailed results for other spray conditions have been published elsewhere $\left[{ }^{11}\right]$.

Powder melting stage depends on the spray distance. Despite the fact that particle temperature is highest at the spray distance of $225 \mathrm{~mm}$, the melting of the particles is not complete yet. Diagnostic study gives only information about the particle surface temperature, and with a too low spray distance and short delay time in the flame the particle is not fully melted. Figure 3 shows this clearly. Melting stage of the particles with the stand-off distance of $300 \mathrm{~mm}$ is much higher compared to the stand-off distances of 150 and $225 \mathrm{~mm}$.

Table 1. HVOF spray parameters

\begin{tabular}{c|c|c|c|c}
\hline Spray condition & $\begin{array}{c}\mathrm{H}_{2}, \\
1 / \mathrm{min}\end{array}$ & $\begin{array}{c}\mathrm{O}_{2}, \\
1 / \mathrm{min}\end{array}$ & $\begin{array}{c}\mathrm{N}_{2}, \\
1 / \mathrm{min}\end{array}$ & $\mathrm{H}_{2} / \mathrm{O}_{2}$ \\
\hline A & 665 & 235 & 22 & 2.83 \\
B & 620 & 280 & 22 & 2.21
\end{tabular}




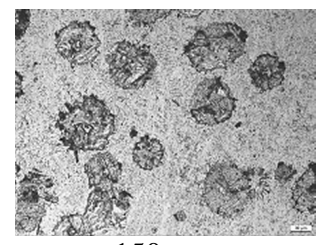

$150 \mathrm{~mm}$

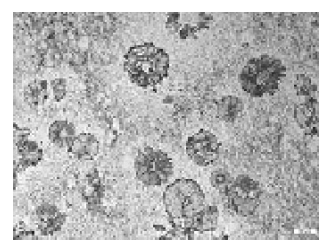

$150 \mathrm{~mm}$

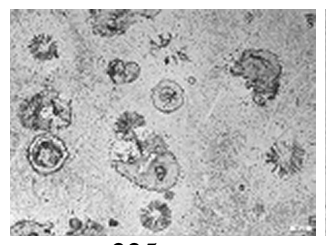

$225 \mathrm{~mm}$

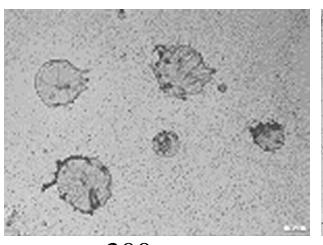

$300 \mathrm{~mm}$

(a)

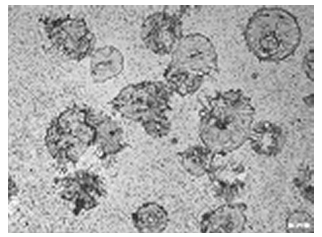

$225 \mathrm{~mm}$

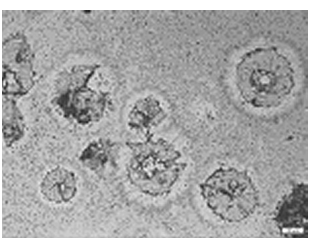

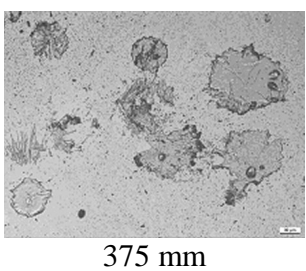

$375 \mathrm{~mm}$

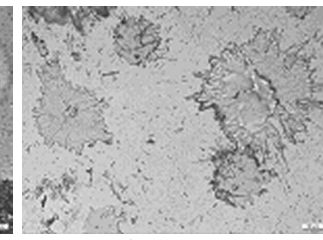

$375 \mathrm{~mm}$

(b)

Fig. 4. Splats obtained with spray conditions A and B in powder BT1with different stand-off distances: $\mathrm{a}$ - spray condition $\mathrm{A} ; \mathrm{b}$ - spray condition $\mathrm{B}$.

\subsection{Coating phase structure and microstructure}

Spray parameter optimization was carried out utilizing splat studies. Based on the spray parameter optimization, stand-off distance of $300 \mathrm{~mm}$ was selected for the test coating preparation. At this spray distance, the melting of particles is extensive enough, while particles still retain high velocity. This is optimal condition to produce a dense coating. Spray distance of $370 \mathrm{~mm}$ showed too low particle total flux as well as low particle velocity, accomplishing poor spray deposition. Both spray conditions, A and B, were used to compare the coating microstructure with different hydrogen-oxygen ratios.

It was found that dense and well-bonded coatings with partial or almost $100 \%$ quasicrystalline microstructure (depending on the coating material) were possible to obtain. A typical microstructure is presented in Fig. 5. Main difference in the

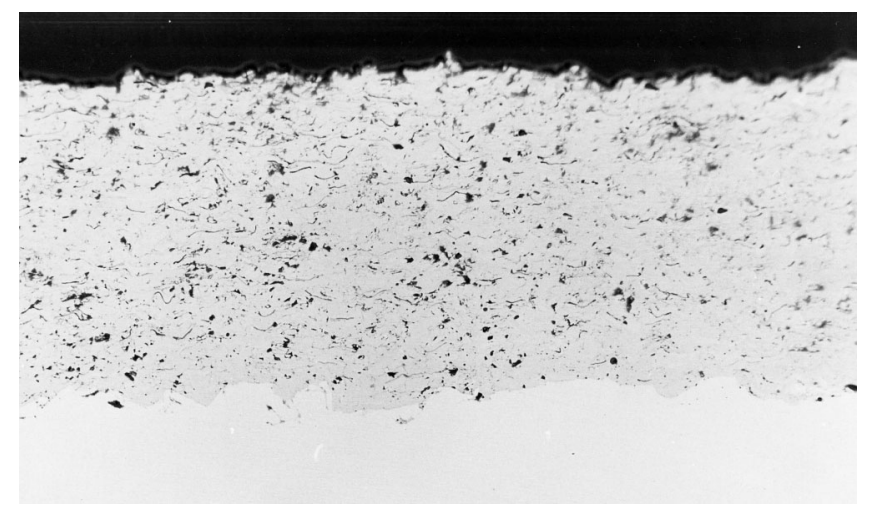

Fig. 5. Typical microstructure for HVOF sprayed quasicrystalline coating $(75 \times$ magnification $)$. 
coatings made by using spray parameters A and B was in the amount of porosity and oxide layers. A detailed summary of microstructures and phase structures of the coatings is given in $\left[{ }^{9,10}\right]$.

In summary, the coating F1 could be deposited only partially quasicrystalline, consisting of quasicrystalline icosahedral $\mathrm{i}-\mathrm{Al}_{65} \mathrm{Cu}_{20} \mathrm{Fe}_{15}$ and crystalline cubic $\beta$-AlFe. It is well known that by applying a heat treatment, the phase structure can be changed $\left[{ }^{12}\right]$. After a heat treatment at $700{ }^{\circ} \mathrm{C}$ for $2 \mathrm{~h}$ in vacuum, the fully icosahedral i- $\mathrm{Al}_{65} \mathrm{Cu}_{20} \mathrm{Fe}_{15}$ coating was obtained.

The coating A1/S had also a two-phase structure, but in this case both phases were quasicrystalline: $\mathrm{Al}_{80} \mathrm{Cr}_{13.5} \mathrm{Fe}_{6.5}$ as well as $\mathrm{Al}_{13} \mathrm{Cr}_{3} \mathrm{Cu}_{4}$. The coating BT1 was most interesting consisting of very rarely reported dodecagonal phase $\mathrm{Al}_{70.6} \mathrm{Co}_{12.5} \mathrm{Fe}_{9.4} \mathrm{Cr}_{7.5}$.

\subsection{Tribological properties}

The PoD-test yielded friction values varying typically between $0.4-0.6$ in practically all cases independent of the counter material. The only exception was the DLC-coated counter part where the PoD-test gave as low friction coefficient as 0.08. As an example, the results of PoD-tests for all coatings at room temperature and at $300^{\circ} \mathrm{C}$ against $\mathrm{M} 2$ tool steel are shown in Fig. 6 . The friction varies between 0.45 and 0.6 . The lowest friction values at room temperature were obtained for $\mathrm{A} 1 / \mathrm{S}(0.45)$. At $500^{\circ} \mathrm{C}$, however, the same coating had the highest friction value, while for the other two coatings the friction coefficient increased only moderately with temperature.

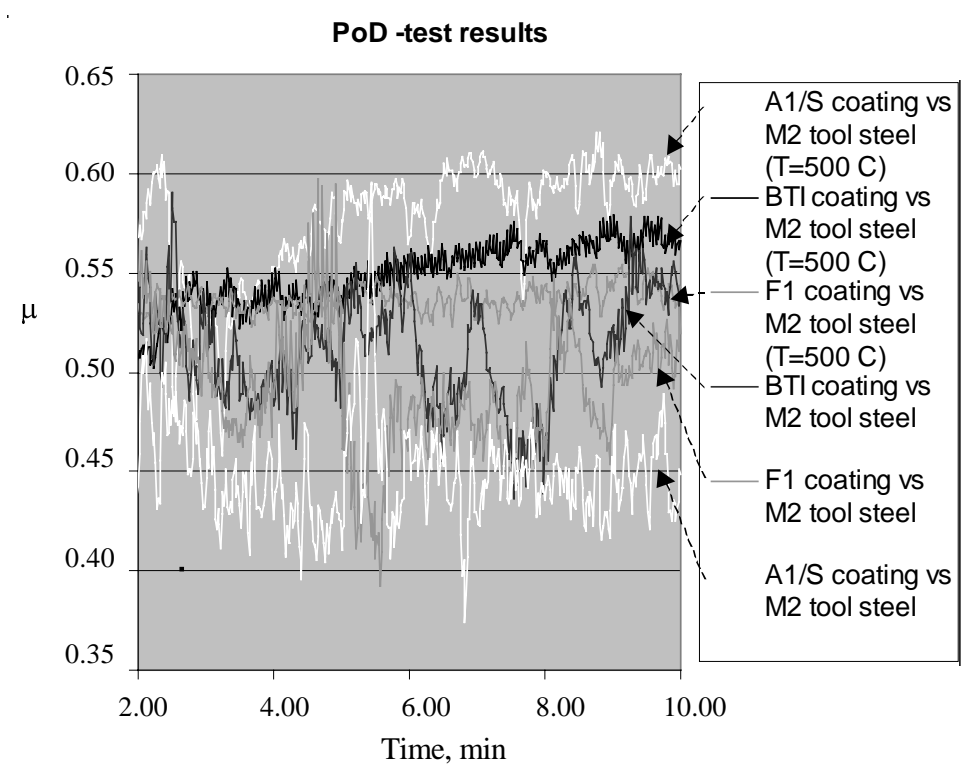

Fig. 6. PoD-test of the QC coatings against M2-steel. 


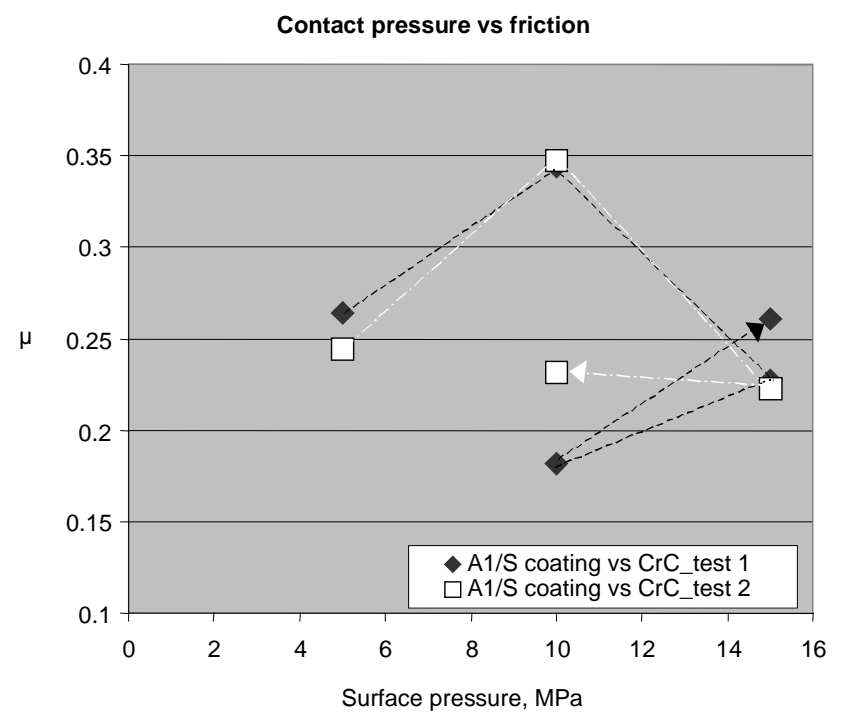

Fig. 7. Average friction vs contact pressure in $\mathrm{A} 1 / \mathrm{S}-\mathrm{CrC}$ contact.

The coefficient of friction for tested quasicrystalline coatings was found to be considerably smaller against the hard coatings at higher surface pressures. In the torsional test the friction varied typically around $0.2-0.3$ against $\mathrm{Cr}_{3} \mathrm{C}_{2}$-NiCr-coated surface and values as low as 0.18 were also occasionally detected (Fig. 7). Also, the coefficient of friction appeared to depend on the contact pressure induced, but not in a straightforward manner.

The scratch test results indicated that low friction values, comparable to those reported in literature for diamond-quasicrystalline contacts, could be obtained for all the test coatings. E.g., the measured value for the BT1 coating was 0.10.

\section{DISCUSSION}

\subsection{Optimization of the spray parameters and characterization of the coating}

Diagnostic studies showed that particle temperatures in the spray are higher with the hydrogen/oxygen ratio of 2.21 than with the ratio of 2.83 . Temperature is highest at the spray distance of $225 \mathrm{~mm}$. Comparison with the single splat studies, however, shows that particles are more melted at the spray distance of $300 \mathrm{~mm}$. This is because the diagnostic studies give only the temperature information from the surface of the particle. Depending on the particle velocity, which determines the time the particle remains in the flame and the thermal conductivity of the material, there is some delay before also the core part of the particle is fully melted. It means that the optimal spraying distance is somewhat longer than that corresponding to the maximum surface temperature of the particles. 
The DTA studies show that the melting temperature for all quasicrystal materials is far below the surface temperatures measured in the diagnostic studies. It can be clearly seen from the single splat morphology that melting is not complete at the spray distances of $150 \mathrm{~mm}$ or $225 \mathrm{~mm}$, despite the fact that the highest surface temperature is measured for the spray distance of $225 \mathrm{~mm}$. Actually, splat studies show that melting of the particles is even higher at the spray distances of $370 \mathrm{~mm}$. However, at this long stand-off distance only few particles are attached any longer to the surface due to the lowered particle velocity. Correspondingly, the deposition efficiency was found to be poor and so big spray distance is not useful. In summary, based on the diagnostics and splat studies, the spray distance of $300 \mathrm{~mm}$ was found to be optimal for the investigated quasicrystal powders when using the HV-2000 HVOF gun.

Test coatings were manufactured by using spray conditions A and B (Table 1) with a stand-off distance of $300 \mathrm{~mm}$. Microstructure and phase studies show that dense, well bonded coatings with a quasicrystalline structure can be produced with both spray conditions. Difference between the coatings made by using spray conditions $\mathrm{A}$ and $\mathrm{B}$ was in the amount of oxidation vs coating density. Spray condition B produced denser coating; however, the amount of oxidation was also higher, obviously due to the higher flame temperature.

As a conclusion from the coating structure optimization it can be said that the alloy F1 is the most sensitive for phase transformations, alloy A1/S forms two different phases but is nevertheless mainly quasicrystalline, and BT1 is the most stable and fully quasicrystalline with a wide range of process parameters.

\subsection{Tribological properties}

Relatively high values of the coefficient of friction were obtained in the PoDtest. These tests yielded friction values varying typically between 0.4-0.6 independently of the counter material. These values are considerably higher than the values reported previously $\left[{ }^{1,8}\right]$. It seems to us that the previous results, obtained mainly from the scratch test, are valid only for the coefficient of friction between the quasicrystalline coating and diamond and cannot be generalized to other counter materials (as has frequently been done in the literature). Such low values of the coefficient of friction were found also in the PoD-tests of the present work when the counter material was diamond-like carbon (DLC). These values, however, are not very different from those obtained in contact between DLC and several other counter materials $\left[^{13,14}\right]$. Some low values of the coefficient of friction are reported previously for other counter materials and these results differ considerably from our results $\left[{ }^{6,7,14}\right]$.

While the coefficient of friction was unexpectedly high at low temperatures, the increase in the temperature up to $500^{\circ} \mathrm{C}$ did not much increase the coefficient of friction. This is an encouraging result regarding the possible use of these coatings at high temperatures. 
Interesting results were obtained also in the torsional testing of the coatings with various counter materials. In general, friction appeared to depend on the contact pressure induced, but not in a straightforward manner as depicted in Fig. 7. The history-dependence of the friction seems to indicate that pressuredependent changes occur in the tribofilm. In certain circumstances this seems to be very beneficial when friction decreases with increasing pressure. This behaviour may be useful in some valve applications.

\section{CONCLUSIONS}

Tribological properties of quasicrystalline coatings, produced by optimized HVOF spraying, were studied. Based on the PoD- and torsional wear tests it can be concluded that quasicrystalline coatings do not show exceptionally high potential for tribological applications against hard or soft metallic materials contrary to the expectations expressed in the literature. However, relatively low friction values can be obtained with quasicrystalline coatings in contact with carbides and DLC-coatings. In addition, very interesting pressure history dependent behaviour of tribofilm formation was detected. This may be useful, e.g., in some valve applications.

\section{ACKNOWLEDGEMENTS}

The authors wish to thank the National Funding Agency TEKES and Nordic Aluminium Oy, Outokumpu Poricopper Oy, Pikoteknik Oy, Andritz Oy, Iittala Oy, Metso Paper Service Oy, and Telatek Oy for their support to this work.

\section{REFERENCES}

1. Dubois, J. M. New prospects from potential applications of quasicrystal materials. Mater. Sci. Eng., 2000, 294-296, 4-9.

2. Huttunen-Saarivirta, E. Microstructure, fabrication and properties of quasicrystalline $\mathrm{Al}-\mathrm{Cu}-\mathrm{Fe}$ alloys: a review. J. Alloys Compounds, 2003 (forthcoming).

3. Besser, M. F. and Eisenhammer, T. Deposition and applications of quasicrystal coating. Mater. Res. Soc. Bull., 1997, 11, 59-64.

4. Sordelet, D. J. and Dubois, J. M. Quasicrystals: Perspectives and potential applications. Mater. Res. Soc. Bull., 1997, 11, 34-37.

5. Fleury, E., Lee, S. M., Kim, W. T., and Kim, D. H. Effects of air plasma spraying parameters on the Al-Cu-Fe quasicrystalline coating layer. J. Non-Crystall. Solids, 2000, 278, 194 204.

6. Lang, C. I., Shechtman, D., and Gonzalez, E. Friction and wear properties of quasi-periodic material coatings. Bull. Mater. Sci., 1999, 22, 189-192.

7. De Palo, S., Usmani, S., Kishi, K., Sampath, S., Sordelet, D. J., and Besser, M. F. Thermal spray quasicrystalline coatings. Part II: Relationships among processing, phase assemblage and tribological response. In Proc. 15th International Thermal Spray Conference. Nice, 1998. 
8. Brunet, P., Zhang, L.-M., Sordelet, D. J., Besser, M., and Dubois, J. M. Comparative study of microstructural and tribological properties of sintered, bulk icosahedral samples. Mater. Sci. Eng., 2000, 294-296, 74-78.

9. Huttunen-Saarivirta, E., Turunen, E., and Kallio, M. Microstructural characterisation of thermally sprayed quasicrystalline Al-Co-Fe-Cr coatings. J. Alloys Compounds, 2003, 354, 269-280.

10. Huttunen-Saarivirta, E., Turunen, E., and Kallio, M. Influence of $\mathrm{Cr}$ alloying on the microstructure of thermally sprayed quasicrystalline Al-Cu-Fe coatings. Intermetallics, 2003, 11, 879-891.

11.Varis, T. and Turunen, E. Optimization of thermal spray parameters of quasicrystalline coatings. VTT report TUO25-032411. Espoo, 2003.

12. De Palo, S., Usmani, S., Sampath, S., Sordelet, D. J., and Besser, M. Friction and wear behavior of thermally sprayed Al-Cu-Fe quasicrystal coatings. In Thermal Spray: A United Forum for Scientific and Technological Advances. ASM International, Materials Park, Ohio, USA, 1997, 135-139.

13. Ronkainen, H., Varjus, S., and Holmberg, K. Friction and wear properties in dry, water- and oil-lubricated DLC against alumina and DLC against steel contacts. Wear, 1998, 222, 120 128.

14. Meletis, E. I., Liu, Y., and Erdemir, A. Influence of environmental parameters on the frictional behavior of DLC coatings. Surface Coatings Technol., 1997, 1-3, 463-468.

\section{Kvaasikristalsete termopinnete pihustusparameetrite optimeerimine ja nende triboloogilised omadused}

\section{Erja Turunen, Tommi Varis, Kari Vierimaa ja Simo-Pekka Hannula}

Kvaasikristalsetel termopinnetel on head triboloogilised omadused ja madal hõõrdekoefitsient. Artiklis on vaadeldud erineva koostisega kvaasikristalsete termopinnete kiirleekpihustusparameetrite optimeerimist ja nende triboloogilisi omadusi, viies läbi diagnostilisi mõõtmisi reaalajas, pulbrilatakate uuringuid ning kulumis- ja hõõrdeeksperimente. Selgitati välja pinnetele omane suhteliselt kõrge hõõrdetegur, mis on piirides $0,4-0,6$ ja sõltub vastaskeha materjalist. 